\title{
Reducing the Nitrogen Footprint of a Small Residential College
}

\author{
Neil Leary, ${ }^{1}$ Elizabeth de la Reguera, ${ }^{2}$ Steven Fitzpatrick, ${ }^{3}$ and Olivia Boggiano-Peterson ${ }^{3}$
}

\section{Abstract}

The release of reactive nitrogen contributes to its accumulation in the environment, causing a variety of harmful effects. To measure Dickinson College's contribution to nitrogen pollution, and quantify the potential to reduce its contribution, we calculated the college's nitrogen footprint and simulated the effects of selected nitrogen mitigation measures. The analysis was obtained using the Nitrogen Footprint Tool, developed at the University of Virginia. Food production is by far the largest contributor to Dickinson's footprint, followed by heat and power. Transportation, sewage, and groundskeeping contribute relatively small amounts. Breaking food down into different food categories, meat and fish is the largest source of nitrogen, accounting for two-thirds of the food footprint. Simulations of individual mitigation measures showed that measures targeting food are the most impactful for reducing the college's nitrogen footprint. Two policy scenarios that combine multiple measures, one representing moderate action and the other more aggressive action, were also analyzed. They are projected to reduce Dickinson's footprint by roughly 15 and 25 percent, respectively, while reducing operating costs. Achieving these reductions would require substantial changes in dietary choices by members of the campus community.

Keywords: campus sustainability; energy; food; nitrogen footprint; nitrogen mitigation; nitrogen pollution

\section{Introduction}

The environmental footprint of Dickinson College, a residential liberal arts college with 2,340 undergraduate students located in southcentral Pennsylvania, includes the release of reactive nitrogen. Activities of the college that cause reactive nitrogen to be released to the environment include feeding its students and employees, heating and powering the campus, traveling for work and study abroad, and maintaining college grounds. Reactive nitrogen release contributes to its accumulation in the environment and a variety of harmful effects that include, for example, eutrophication of surface waters, acid rain, forest dieback, biodiversity loss, smog, and global climate change. ${ }^{1,2}$

Seeking to understand and quantify Dickinson's contribution to excess reactive nitrogen in the environment, de la Reguera calculated Dickinson's nitrogen footprint for fiscal year 2011 (FY11) for a senior thesis research project, supervised by Leary. ${ }^{3}$ The calculation utilized a preliminary version of the Nitrogen Footprint Tool (NFT) that was developed by Leach and colleagues and applied by them to calculate the first institutional nitrogen footprint for the University of Virginia (UVA). ${ }^{4}$ The collaboration with UVA resulted in Dickinson being invited to be one of the first members of the Nitrogen Footprint Tool Network, a network that has grown to include 20 institutions. ${ }^{5}$ 
De la Reguera's initial results and information about the Nitrogen Footprint Tool Network were presented to Dickinson's presidential commission on environmental sustainability in fall 2014, which requested further study of the college's nitrogen footprint and options for reducing its footprint. Responding to the commission's request, Leary, de la Reguera, and Dickinson students Fitzpatrick and Boggiano-Peterson formed a research team to update and extend de la Reguera's work by calculating footprints for fiscal years 2014 (FY14) and 2015 (FY15) and analyzing actions for reducing the college's creation and release of reactive nitrogen to the environment.

\section{Methods and Data Inputs}

The nitrogen footprint was calculated for Dickinson College for fiscal years FY14 and FY15 using version 2.1 of the NFT, which is documented in the NFT User's Manual. ${ }^{6}$ Conceptually, the tool is similar to the Clean Air-Cool Planet Campus Carbon Calculator, a tool that Dickinson and many other colleges and universities use to calculate greenhouse gas emission inventories. ${ }^{7}$ The methods and data used to calculate Dickinson's nitrogen footprint are briefly described here.

Data for the college are input to the NFT for activities that release reactive nitrogen to the environment. NFT manipulates the input data to calculate an estimate of the institution's footprint of reactive nitrogen in kilograms (kg) of nitrogen. NFT is populated with default factors for converting the input data to reactive nitrogen releases that are based either on national averages or conditions specific to the University of
Virginia. The user may revise factors to reflect conditions at the user's institution. Emission factors specific to Dickinson and its surrounding region are used in place of NFT default factors for $\mathrm{N}_{2} \mathrm{O}$ and $\mathrm{NOx}$ emissions from fuels and electricity generation, as well as for the rate of reactive nitrogen removal at the local sewage treatment plant.

Dickinson has one main dining hall and a small number of other venues at which food is served to students, 94 percent of whom live on campus and have full meal plans, employees who purchase some of their meals from campus venues, and participants in summer programs hosted by the college. Foods served by the college cause releases of reactive nitrogen to the environment through a number of pathways: virtual reactive nitrogen that is lost to the environment upstream of the college from growing, harvesting and processing purchased foods; reactive nitrogen that is emitted by burning fuels to transport foods from processors to campus; reactive nitrogen contained in food waste sent to the landfill; and reactive nitrogen contained in food that is consumed, passed to the Carlisle sewage treatment plant, and not converted back to nitrogen gas by treatment processes. Denitrification processes at the Carlisle sewage treatment plant convert 88 percent of reactive nitrogen to inert nitrogen gas, while 12 percent is released in a reactive form.

Nearly all food waste in the main dining hall is diverted from the landfill for composting. Pre- and postconsumer food waste is captured in the kitchen, processed through a pulper that grinds the waste and removes water, and transported to the
Dickinson College Farm, a 50-acre sustainably managed organic-certified farm, where it is composted and used as a soil amendment to grow food for the campus and Carlisle community. In FY15, 171 metric tons of food waste (weight before pulping and removing water) was composted at the Dickinson farm. Composted food waste is excluded from the nitrogen footprint by the NFT because it reuses the nitrogen.

Dickinson's food purchase data for FY14 and FY15 are reported in Table 1 and displayed in Figure 1. Table 1 also presents factors used in the NFT to calculate reactive nitrogen releases through different food pathways. Key among these is the Virtual Nitrogen Factor (VNF), which is an estimate of the amount of reactive nitrogen that is lost to the environment upstream of the buyer relative to the nitrogen content of the purchased food.

Dickinson's dining services provided the food purchase data in the form of Microsoft Excel spreadsheets containing more than 30,000 entries for each year. Each entry had to be assigned to one or more of 18 food categories as defined by the Food and Agriculture Organization, ${ }^{10}$ units converted to $\mathrm{kg}$ of food weight, and aggregated for each category. The aggregation was automated using a JavaScript code.

Food purchases totaled 1,068,585 kg in FY14 and 1,199,777 kg in FY15, a 12.3 percent increase from one year to the next. Included in the Dining Services food purchase data are purchases made from the Dickinson College Farm. Reactive nitrogen losses from college farm operations that are associated with produc- 


\begin{tabular}{|c|c|c|c|c|c|c|c|}
\hline \multicolumn{2}{|c|}{ Food category } & FY14 Food & FY15 Food & Average & & Average & Food \\
\hline \multirow{4}{*}{$\begin{array}{l}\text { Meat } \\
\text { \& Fish }\end{array}$} & Poultry & 60,949 & 65,265 & 0.25 & 2.7 & 950 & 15 \\
\hline & Beef & 71,603 & 77,433 & 0.28 & 6.9 & 950 & 15 \\
\hline & Pork & 69,877 & 69,087 & 0.25 & 3.8 & 950 & 15 \\
\hline & Fish & 81,910 & 63,454 & 0.21 & 2.4 & 950 & 39 \\
\hline \multirow{3}{*}{$\begin{array}{l}\text { Dairy } \\
\text { \& Eggs }\end{array}$} & Milk & 113,660 & 133,517 & 0.05 & 3.6 & 65 & 15 \\
\hline & Cheese & 58,866 & 61,750 & 0.18 & 3.6 & 65 & 15 \\
\hline & Eggs & 23,009 & 23,591 & 0.13 & 3.8 & 65 & 15 \\
\hline \multirow{3}{*}{$\begin{array}{l}\text { Cereals, } \\
\text { Pulses } \\
\& \text { Nuts }\end{array}$} & Cereals & 87,277 & 103,674 & 0.07 & 0.6 & 1350 & 28 \\
\hline & Pulses & 21,249 & 24,846 & 0.05 & 0.4 & 1500 & 5 \\
\hline & Nuts & 974 & 1523 & 0.13 & 0.4 & 1500 & 5 \\
\hline \multirow{3}{*}{\begin{tabular}{|l|} 
Fruits, \\
Vegetables \\
\& Roots
\end{tabular}} & Fruits & 101,823 & 130,908 & 0.01 & 7.7 & 1500 & 37 \\
\hline & Vegetables & 168,098 & 181,822 & 0.02 & 7.7 & 1500 & 37 \\
\hline & $\begin{array}{l}\text { Starchy } \\
\text { roots }\end{array}$ & 42,127 & 51,173 & 0.02 & 0.8 & 1500 & 35 \\
\hline \multirow{5}{*}{$\begin{array}{l}\text { Oils, Sugars } \\
\& \text { Other }\end{array}$} & Oil crops & 29,708 & 34,772 & 0.06 & 7.7 & 800 & 5 \\
\hline & $\begin{array}{l}\text { Sugar } \\
\text { crops }\end{array}$ & 49,176 & 80,919 & 0.00 & 7.7 & 800 & 37 \\
\hline & Stimulants & 7,625 & 14,487 & 0.00 & 7.7 & 800 & 37 \\
\hline & Spices & 2,279 & 3,433 & 0.13 & 7.7 & 800 & 37 \\
\hline & Beverages & 78,375 & 77,583 & 0.001 & 7.7 & 800 & 37 \\
\hline \multicolumn{2}{|c|}{ Total Food Purchases } & $1,068,585$ & $1,199,777$ & & & & \\
\hline
\end{tabular}

${ }^{a}$ Average protein content from Leach et. al. ${ }^{4}$, derived from the USDA Nutrient Database for Standard Reference. ${ }^{b}$ Virtual nitrogen factors from Leach et. al. ${ }^{4}$.

${ }^{c}$ Average distance that food products travel prior to consumption from Leach et al. (2013) are based on Hendrickson. ${ }^{8}$ ${ }^{d}$ Percent of food available for consumption that is not actually consumed are derived by Leach et. al. ${ }^{4}$ from Food and Agriculture Organization. ${ }^{9}$

ing the food sold to college dining services are implicitly reflected in the $\mathrm{N}$ footprint calculations, assuming that VNFs for the Dickinson farm are equal to those for conventional farms.

Data inputs for other activities that contribute to Dickinson's nitrogen footprint are reported in Table 2 . Dickinson burns natural gas and distillate oil in its central energy plant and other equipment to provide space heat and hot water to the campus. Dickinson also purchases electricity from our local utility, PPL Electric Utilities, to power the campus. Roughly 60 percent of purchased electricity is generated by burning fossil fuels; 43 percent coal, 17 percent natural gas and 0.25 percent oil. The high temperatures used to burn fossil fuels create reactive nitrogen as nitrous oxide $\left(\mathrm{N}_{2} \mathrm{O}\right)$, a potent greenhouse gas, and nitrogen oxides (NOx), an air pollutant that contributes to ground-level ozone formation, acid rain, and airborne particulate matter. ${ }^{2}$ These air emissions contribute to the college's $\mathrm{N}$ footprint.

Transportation activities of the college also emit $\mathrm{N}_{2} \mathrm{O}$ and $\mathrm{NOx}$. These activities include use of college fleet vehicles by college employees and students; use of college vehicles by Facilities Management for campus maintenance; air travel by employees for college business; air travel by students for study abroad and athletic events; and commuting by college employees.

Finally, Dickinson releases reactive nitrogen through the application of synthetic nitrogen fertilizers on college grounds at the main campus and organic fertilizers at the Dickinson College Farm. A portion of the nitrogen content of these fertilizers is taken up by vegetation on a multiyear basis, while the rest is released to the environment. An estimate of the amount of nitrogen released from fertilizers is included in Dickinson's footprint.

\section{Nitrogen Footprints for FY14 and FY15}

Dickinson College caused 84.8 metric tons of reactive nitrogen to be released to the environment in FY14 and 87.7 metric tons $\mathrm{N}$ in FY15 (Table 3). The 3.5 percent increase in total nitrogen from FY14 to FY15 is driven by an increase in food purchases. While food purchases rose 12.3 percent by weight, the $\mathrm{N}$ footprint associated with food purchases rose only 5.0 percent as purchases of nitrogen intensive meat and fish declined slightly. 


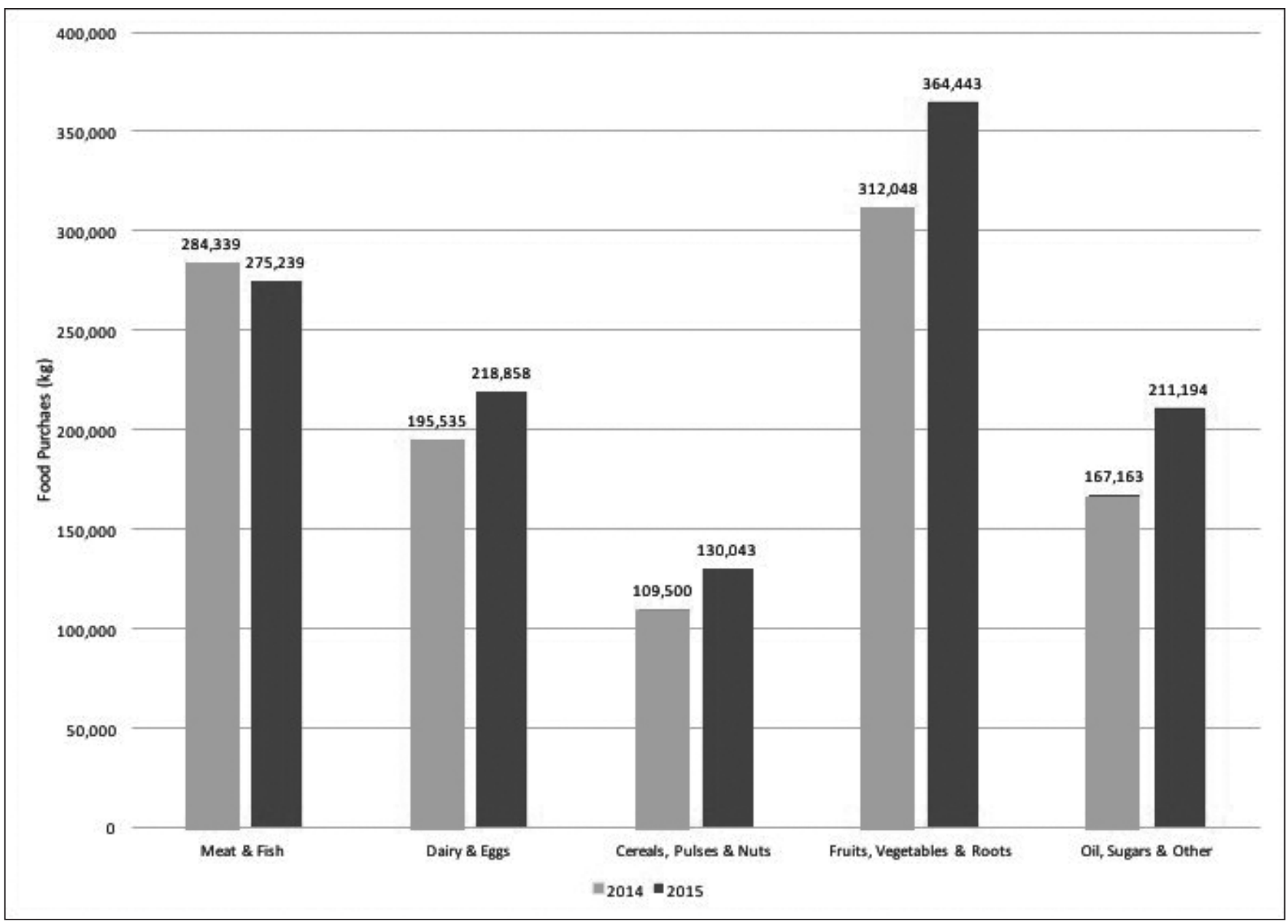

Figure 1. Food purchases, 2014 and 2015

\section{Table 2. Data Inputs for Heat and Power, Transportation and Groundskeeping}

\begin{tabular}{|l|l|r|r|}
\hline \multirow{4}{*}{ Heat \& power } & & FY14 & \multicolumn{1}{|c|}{ FY15 } \\
\cline { 2 - 4 } & Natural gas (mmBtu) & 89,157 & 89,314 \\
\cline { 2 - 4 } & Distillate oil (gal) & 50,727 & 35,588 \\
\cline { 2 - 4 } & Electricity (kWh) & $20,013,835$ & $19,748,292$ \\
\hline \multirow{3}{*}{ ransportation } & College gasoline (gal) & 34,072 & 33,214 \\
\cline { 2 - 4 } & College diesel (gal) & 5,458 & 6,469 \\
\cline { 2 - 4 } & Employee commuting (mi) & $4,850,351$ & $4,375,161$ \\
\cline { 2 - 4 } & Air travel - employees (mi) & 795,145 & 724,667 \\
\cline { 2 - 4 } & Air travel students (mi) & $4,850,351$ & $3,758,432$ \\
\hline Groundskeeping & Fertilizer (lbs N) & 6,394 & 5,951 \\
\hline
\end{tabular}

Food is by far the largest contributor to Dickinson's footprint, accounting for 79.5 percent in FY15, followed by heat and power (14.1 percent); transportation (2.6 percent); sewage (2.1 percent); and groundskeeping
(1.7 percent) as shown in Figure 2. Breaking food down into different food categories, meat and fish is the largest source of nitrogen, contributing 67.4 percent of the food footprint in FY15. Meat and fish are followed by dairy and eggs (17.9 percent); fruits, vegetables and roots (8.4 percent); oils, sugars and other foods (5.1 percent); and cereals, pulses and nuts (1.2 percent). The large footprint for meat reflects not just the quantity of meat purchased and consumed, but also, and importantly, the larger inputs of fertilizers and other resources for animal feed needed per $\mathrm{kg}$ of meat protein supplied relative to other foods, as reflected by their high VNFs, and their high protein content by weight.

As noted previously, there are four pathways by which foods served at Dickinson release nitrogen to the environment. Virtual nitrogen, released upstream of the college from growing, harvesting and processing purchased foods, is by far the largest, 


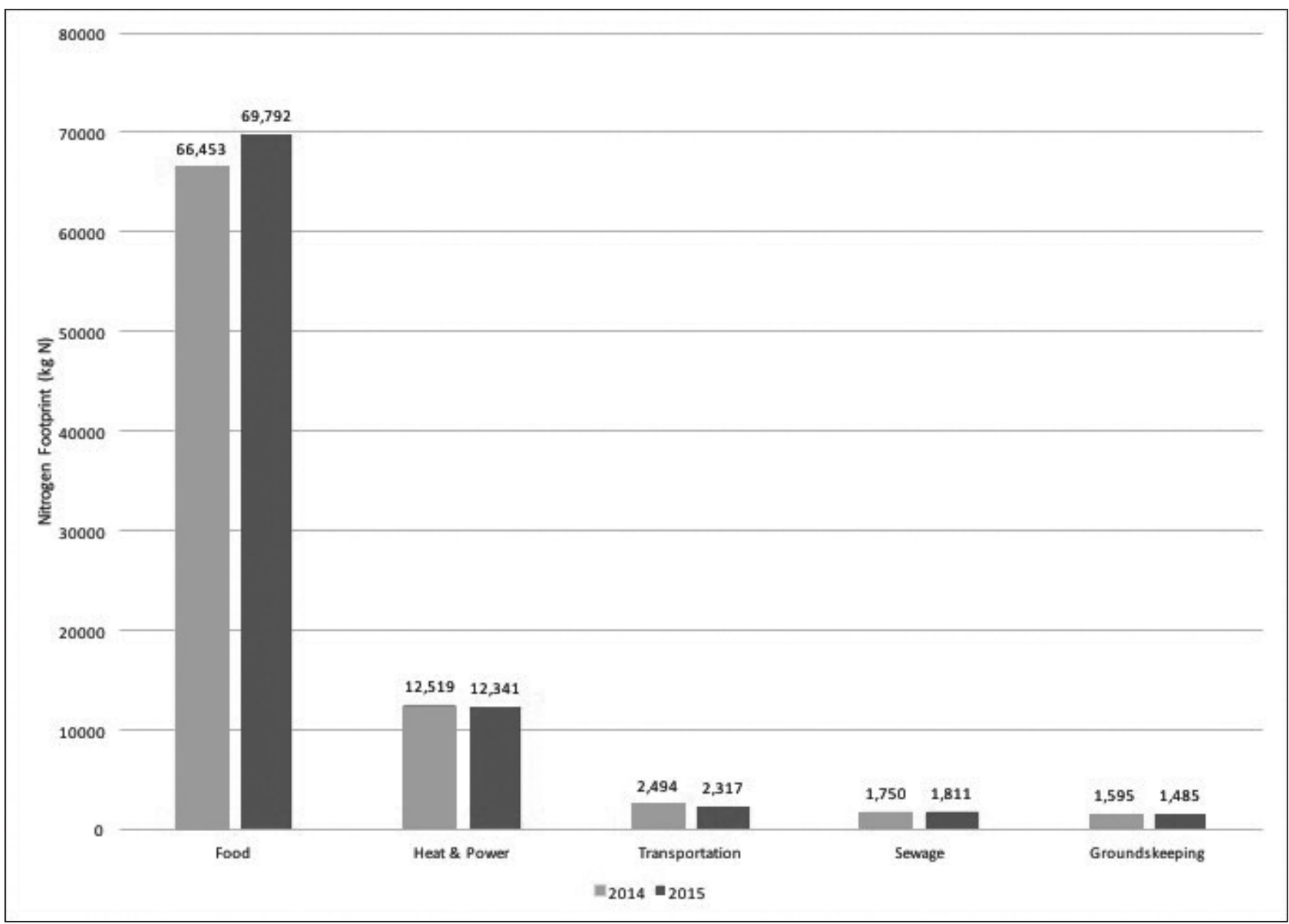

Figure 2. Nitrogen footprint by major source, 2014 and 2015

\section{Table 3. Nitrogen Footprint for Dickinson College, FY14 and FY15}

\begin{tabular}{|l|l|r|r|r|}
\hline \multicolumn{2}{|l|}{ Source } & $\begin{array}{r}\text { FY14 } \\
(\mathrm{kg} \mathrm{N})\end{array}$ & $\begin{array}{c}\text { FY15 } \\
(\mathrm{kg} \mathrm{N})\end{array}$ & $\begin{array}{c}\text { Percentage } \\
\text { Change }\end{array}$ \\
\hline \multirow{2}{*}{ Food } & Meat \& fish & 46,252 & 47,034 & $1.69 \%$ \\
\cline { 2 - 5 } & Dairy \& eggs & 11,529 & 12,515 & $8.55 \%$ \\
\cline { 2 - 5 } & Cereals, pulses \& nuts & 713 & 867 & $21.60 \%$ \\
\hline \multirow{3}{*}{ Food - sewage } & Fruits, vegetables \& roots & 5,154 & 5,838 & $13.27 \%$ \\
\cline { 2 - 5 } & Oils, sugars \& other foods & 2,805 & 3,538 & $26.13 \%$ \\
\cline { 2 - 5 } & Food subtotal & 66,453 & 69,792 & $5.02 \%$ \\
\hline \multirow{3}{*}{ Heat \& power } & Electricity & 1,750 & 1,811 & $3.49 \%$ \\
\cline { 2 - 5 } & On-campus heat \& power & 11,842 & 11,684 & $-1.33 \%$ \\
\cline { 2 - 5 } & Heat \& power subtotal & 12,519 & 12,342 & $-1.42 \%$ \\
\hline \multirow{2}{*}{ Transportation } & College owned vehicles & 274 & 302 & $10.22 \%$ \\
\cline { 2 - 5 } & Employee commuting & 958 & 864 & $-9.81 \%$ \\
\cline { 2 - 5 } & Air travel & 1,262 & 1,151 & $-8.80 \%$ \\
\cline { 2 - 5 } & Transportation subtotal & 2,494 & 2,317 & $-7.10 \%$ \\
\hline Groundskeeping & & 1,595 & 1,485 & $-6.90 \%$ \\
\hline & & 84,811 & 87,746 & $3.46 \%$ \\
\hline
\end{tabular}

contributing an estimated 69.4 metric tons $\mathrm{N}$ in FY15. In comparison, other food-related nitrogen releases are 0.11 metric tons from transporting food, 0.33 metric tons from sending food waste to a landfill, and 1.58 metric tons from consumed food that enters the sewage system and is not denitrified by the sewage treatment process. These results indicate that, while there are many benefits from sourcing food locally and reducing food miles, shifting food purchases to more local sources would have a minimal effect on Dickinson's nitrogen footprint.

The estimated footprints for FY14 and FY15 provide a baseline against which to measure future changes and the performance of nitrogen mitigation measures as may be adopted by the college. 


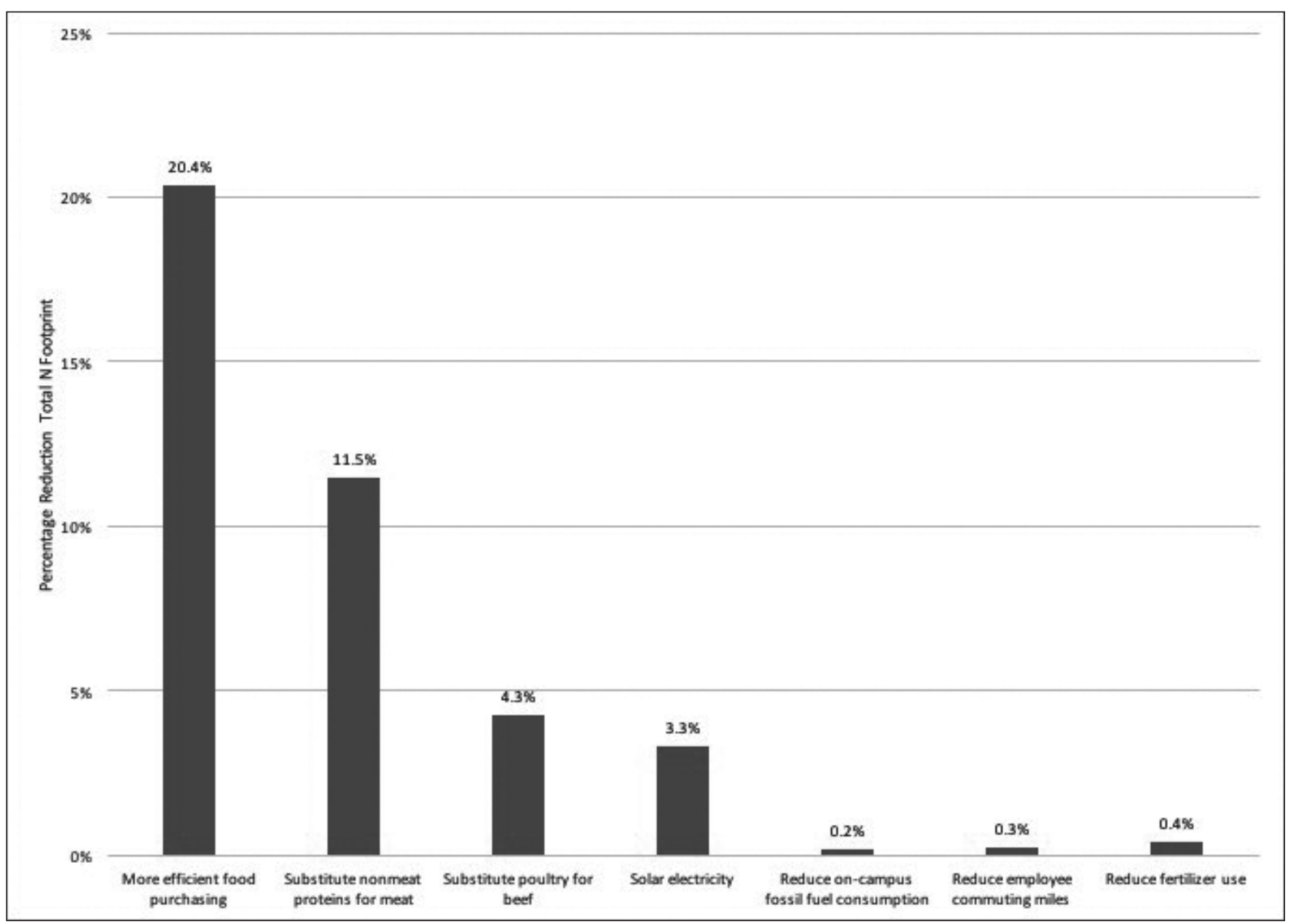

Figure 3. Scenario analyses of nitrogen reduction measures

\section{Simulation of Nitrogen Reduction Measures}

A variety of options are available for reducing Dickinson's nitrogen footprint. Energy conservation and transition from fossil to renewable energies, actions that many institutions are taking to reduce their carbon footprints, can also reduce their nitrogen footprints by reducing emissions of nitrous oxide and nitrogen oxides. ${ }^{11,12}$ More efficient meal planning and preparation to better match diners' preferences can reduce food purchases, yielding corresponding decreases in upstream virtual nitrogen as well as decreases in downstream nitrogen from reduced food waste. Promoting dietary changes is an underuti- lized but potentially effective means of reducing the environmental impacts of food systems. ${ }^{13}$ Menu changes and other measures that encourage diners to choose protein sources with low VNFs in place of sources that have high factors can reduce upstream reactive nitrogen releases. For example, substituting poultry, fish, pork, dairy, and eggs for beef; or beans and grains for meat can provide protein to diners while reducing upstream virtual or beans and grains formed nitrogen.

Other mitigation strategies include promoting employee commuting by modes other than driving in single-occupant motor vehicles and reducing use of fertilizers for groundskeeping.
Using the NFT, scenario analyses were conducted to estimate the effects of selected nitrogen mitigation measures on Dickinson's footprint and identify measures that are particularly impactful. Analyzed measures include 1.) reducing total food purchases 25 percent through improved efficiencies in dining services, 2.) reducing meat purchases 25 percent and substituting non-meat sources of protein, 3.) reducing beef purchases 25 percent and substituting poultry, 4.) sourcing 25 percent of electricity from solar power, 5.) reducing on-campus fossil fuel consumption 25 percent, 6.) reducing employee commuting miles 25 percent and 7.) reducing fertilizer use 25 percent. 
Implementation of each nitrogen mitigation measure was simulated in isolation by modifying corresponding data inputs to the NFT. Percentage changes in the total nitrogen footprint are calculated relative to the FY15 footprint and are presented in Figure 3.

Measures focused on the foods we eat are the most impactful. Purchasing less food overall and shifting purchases away from protein sources that have high virtual nitrogen factors to sources with lower factors can yield substantial reductions. Also impactful is sourcing electricity from solar power. Reducing on-campus fossil fuel consumption, employee commuting miles, and fertilizer use yield very slight reductions in the nitrogen footprint. While these latter measures have little benefit in terms of the college's nitrogen footprint, it should be noted that they can yield other important benefits by reducing greenhouse gas emissions and local air and water pollutants.

The effects of two policy scenarios were also simulated, one moderate and one aggressive. These scenarios combine five selected mitigation measures implemented together. The included measures are the four measures found most impactful in the simulations of individual measures, plus reducing fertilizer use. Reducing fertilizer use is included because, while it has only a small effect on the total nitrogen footprint of the college, it can directly benefit local waterways. The moderate and aggressive policy scenarios differ in the targets set for percentage changes relative to the baseline conditions. The targets in the moderate policy scenario would require concerted effort and modest but significant changes in dietary choices of diners, primarily students. The targets for the aggressive policy scenario call for greater changes and would be more challenging to achieve.

Details of the policy scenarios and results of simulations conducted with NFT are presented in Table 4. The moderate policy scenario is estimated to reduce Dickinson's nitrogen footprint 13.1 metric tons $\mathrm{N}$, or 14.6 percent. In comparison, the aggressive policy scenario is estimated to yield a reduction of 23.1 metric tons $\mathrm{N}$, or 25.8 percent.

\section{Discussion and Conclusion}

The most impactful measure, reducing food purchases through improved efficiencies in dining services, would yield cost savings while also reducing nitrogen pollution. Dickinson's dining services, having invested in and piloted a new database system in FY16 for menu planning and management of purchasing, is already making efforts to improve purchasing efficiencies. While adoption of the new database system was not motivated by environmental goals, it is expected to yield reductions in food purchases and food waste per student, which will reduce both nitrogen and carbon footprints at Dickinson while also reducing food expenditures. Future analysis will evaluate the performance of the system in terms of its effect on Dickinson's nitrogen footprint as well as college finances. The results are expected to assist in assessing the feasibility of meeting the moderate and aggressive policy scenario targets for food purchasing.

Also promising are changes in menus and dietary choices that substitute sources of protein with low VNFs for sources with high factors.
These changes can also reduce food expenditures as well as carbon pollution by substituting poultry, fish, and pork for beef, or substituting grains, legumes, dairy, and eggs for meat. However, imposing dietary changes on students conflicts with the goals of a residential liberal arts college to promote agency and autonomy of its students, and could meet with resistance from students.

Alternatively, students might challenge each other to help develop and implement strategies to promote voluntary changes in dietary choices. Dining services can support these efforts by developing expanded menu options that appeal to students while featuring foods with small nitrogen and carbon footprints while also providing nutritional information to help students make choices that do not compromise their health. Achieving a 10 percent reduction in meat consumption, coupled with a shift away from beef to other forms of meat, would require an effective, well-coordinated, and sustained campaign. Achieving a 25 percent reduction would require even greater effort and a substantial cultural shift at Dickinson.

Sourcing 20 percent of electricity from solar power might seem to be a challenging and costly option. However, Dickinson has recently entered into a power purchasing agreement for a $3 \mathrm{MW}$ solar array to be installed on college-owned property in FY17, which will supply more than 20 percent of Dickinson's annual electricity consumption. Financial analyses indicate that the solar agreement will reduce the college's electric utility costs while also moving the college toward its commitment to be carbon neutral by 2020. Sourcing 30 percent of Dickinson's electricity from solar, as called for in the ag- 
Table 4. Combined Policy Scenarios for Nitrogen Footprint Reduction

\begin{tabular}{|c|c|c|}
\hline Policy Scenario & \multicolumn{2}{|c|}{ Nitrogen Reduction } \\
\hline $\begin{array}{l}\text { Moderate } \\
\text { - Higher purchasing efficiencies reduce total food purchases } 5 \% \\
\text { - Reduce beef purchases } 10 \% \text {, substitute poultry } \\
\text { - Reduce meat purchases } 10 \% \text {, substitute non-meat proteins } \\
\text { - Source } 20 \% \text { of electricity from solar } \\
\text { - Reduce fertilizer use } 10 \%\end{array}$ & $(\mathrm{~kg} \mathrm{~N})$ & 14.6 \\
\hline $\begin{array}{l}\text { Aggressive } \\
\text { - Higher purchasing efficiencies reduce total food purchases } 10 \% \\
\text { - Reduce beef purchases } 25 \% \text {, substitute poultry } \\
\text { - Reduce meat purchases } 25 \% \text {, substitute non-meat proteins } \\
\text { - Source } 30 \% \text { of electricity from solar } \\
\text { - Reduce fertilizer use } 20 \%\end{array}$ & 23,060 & 25.8 \\
\hline
\end{tabular}

gressive policy scenario, would require another project at a later date.

Dickinson already strives to limit the application of nitrogen-containing fertilizers by using clippings, compost, and mulch as nutrient sources as well as other sustainable practices for managing college grounds. Reducing nitrogen fertilizer applications an additional 10 or 20 percent will likely be challenging in consequence.

Grouping individual measures into policy packages representing different degrees of effort or difficulty provides decision makers with information that can be used to evaluate and set targets for reducing nitrogen pollution. The measures included in the moderate policy scenario are feasible and can be implemented at negative financial cost to yield close to an estimated 15 percent reduction in Dickinson's nitrogen footprint. Achieving this benchmark would require completing the planned $3 \mathrm{MW}$ solar installation and implementing a campaign to change dietary choices that is embraced by many students, is supported by menu changes by Dining Services, and is moderately effective. Motivating dietary changes is likely to prove difficult and the resources that would be required to promote changes effectively have not been examined. Reaching the more ambitious benchmark of the aggressive policy scenario would require a renewable electricity project beyond what is currently in progress and a transformative behavior change campaign that engages the entire campus community, including both students and employees. Next steps include presentation of the results to and discussion of options with Dickinson's presidential commission on environmental sustainability, dining services, student organizations, and other campus stakeholders.

\section{Acknowledgments}

This research was supported by grants from Dickinson College's Sustainability Education Fund and Research and Development Committee. Marcus Welker and Jennifer Whitcomb assisted with data collection. The work benefitted from collaboration with the Nitrogen Footprint Tool Network and from advice and comments from Elizabeth Castner, James Galloway, and Allison Leach. The Nitrogen Footprint Tool Network is led by the University of Virginia and is funded by Cooperative Agreement No. 83563201 awarded by the U.S. Environmental Protection Agency.

\section{Author Disclosure Statement}

No competing financial interests exist.

\section{References}

1. Galloway J, Winiwarter W, Leip A, et al. Nitrogen footprints: Past, present and future. Environ Res Lett 2014;9:1-11.

2. Galloway JN, Aber JD, Erisman JW, et al. The nitrogen cascade. Bioscience 2003;53:341-356.

3. de la Reguera E. The nitrogen footprint of Dickinson College. Senior thesis, Dickinson College, Carlisle, PA, 2014.

4. Leach A, Majidi A, Galloway J, et al. Toward institutional sustainability: A nitrogen footprint model for a university. Sus J Record 2013;6:211219.

5. Castner E, Leach A, Leary N, et al. The Nitrogen Footprint Tool Network: A multi-institution program to reduce nitrogen pollution. Sus J Record 2017;10:79-88.

6. Leach A, Majidi A, Galloway J et al. How to calculate your institution's nitrogen footprint. NFT Users' Manual. University of Virginia, Department of Environmental Sciences, Charlottesville, 2014.

7. University of New Hampshire, Clean Air-Cool Planet Calculator. http://sustainableunh.unh.edu/calculator (last accessed 2/27/2017). 8. Hendrickson, J. Energy Use in the U.S. Food System: A Summary of Existing Research and Analysis. www.cias.wisc.edu/wpcontent/uploads/2008/07/energyuse (last accessed 2/26/2017).

9. Food and Agriculture Organization of the United Nations. Global Food Losses and Food Waste. http:// www.fao.org/docrep/014/mb060e/ mb060e00.pdf (last accessed 2/26/2017). 
10. Food and Agriculture Organization of the United Nations. Definition and Classification of Commodities. http://www.fao.org/es/faodef/faodefe.htm (last accessed 3/01/2017). 11. Leach AM, Galloway JN, Castner EA, et. al. An integrated tool for calculating and reducing institution carbon and nitrogen footprints. Sus
J Record 2017;10:140-148.

12. Barnes RT, Andrews J, Orr CC. Leveraging the nitrogen footprint to increase campus sustainability. Sus J Record 2017;10:131-139. 13. Garnett T. Plating up solutions: Can eating patterns be both healthier and more sustainable? Science 2016;353:1202-1204.
Address correspondence to:

Neil Leary

Director, Center for

Sustainability Education

Dickinson College

PO Box 1773

Carlisle, PA 17013

E-mail: learyn@dickinson.edu 